\title{
FORMAÇÃO, CIDADANIA E MERCADO DE TRABALHO: perspectivas de pessoas em formações subsidiadas
}

\author{
Luciana Lopes \\ Universidade do Porto, Portugal \\ Norberto Ribeiro \\ Universidade do Porto, Portugal \\ Carla Malafaia \\ Universidade do Porto, Portugal
}

\begin{abstract}
Resumo
Este artigo visa analisar a relação entre conceções de cidadania e perceções sobre o mercado de trabalho de pessoas a frequentarem formações subsidiadas. Adotou-se uma metodologia qualitativa, com recurso à análise de dez entrevistas. Os resultados mostram que as pessoas em situação de desemprego a frequentar uma formação subsidiada tendem a expressar baixas expectativas relativamente à eficácia destas formações na reinserção profissional, particularmente face a um mercado de trabalho considerado precário e discriminatório. Adicionalmente, apresentam conceções normativas e convencionais sobre a cidadania, que entendem como estando sobretudo ligada ao cumprimento de deveres e obrigações (votar, pagar impostos, estar em formação e ter um emprego). As implicações decorrentes da vivência de uma cidadania alicerçada na iminência da exclusão e do défice devem ser objeto de reflexão política, pois o carácter obrigatório das medidas de ativação pode estar a reforçar fragilidades sociais e ontológicas.
\end{abstract}

Palavras-chave: educação de adultos; formação; cidadania; mercado de trabalho

\begin{abstract}
This paper seeks to analyse the relationship between the understandings of citizenship and the job market of the people who attend subsidised training programmes. To that end, a qualitative methodology was adopted, and 10 semi structured interviews were analysed. The results reveal that unemployed people attending subsidised training programmes tend to express low expectations regarding the efficacy of training in their professional reintegration, facing a precarious and discriminatory labour market. Additionally, they reveal normative and conventional views of citizenship, mainly related to the fulfilment of duties and obligations (vote in elections, pay taxes, be enrolled in training and have a job). The implications of a citizenship grounded on the imminency of exclusion and deficit must be considered politically, under the risk of the mandatory nature of activation measures reinforce social and ontological fragilities.
\end{abstract}

Key words: Adult educational; Training; Citizenship; Labour market 


\section{Introdução}

Estudos anteriores indicam que as medidas de emprego e formação com vista à “ativação" de pessoas desempregadas conduzem frequentemente a um envolvimento instrumental nas formações por risco de perda do subsídio de desemprego (SILVA, 2015). Não obstante, a investigação também evidencia que os grupos menos escolarizados tendem a ser os mais afetados por contextos de crise económica e de desemprego (RIBEIRO, 2018), sendo também os que revelam maior desconfiança relativamente à democracia e seus mecanismos de participação (MALAFAIA, 2011). Por conseguinte, tendo em conta a importância sociopolítica atribuída à educação e formação na construção de cidadãos/ãs ativos/as e considerando também o crescente papel do trabalho como organizador social e orientador de projetos individuais (SILVESTRE, 2012), o presente estudo visa perceber de que modo é que as pessoas envolvidas em formações obrigatórias (e, portanto, pessoas previamente sinalizadas como estando em situações económicas e profissionais de fragilidade), perspetivam a cidadania e o mercado de trabalho.

Nos últimos anos, tem-se verificado um crescente investimento no setor da formação e também a sua maior procura por parte dos indivíduos e das empresas. Isto deve-se ao facto de os indivíduos procurarem situações de empregabilidade e remuneração mais estáveis, mas também à circunstância de as empresas procurarem mão-de-obra qualificada (BRANDÃO, MARQUES, 2013). Os níveis de formação/educação e a situação face ao mercado de trabalho são fatores determinantes de inclusão/exclusão social, com implicações óbvias no rendimento, mas também na realização pessoal e no exercício da cidadania (RAMOS, 2007; RIBEIRO, 2018). Apesar de a problemática do desemprego não ser objeto central de análise neste artigo, deve referir-se que todos/as os/as participantes do estudo estavam em situação de desemprego. Com base em dez entrevistas, o presente artigo visa analisar as perceções dos/as participantes sobre a sua experiência de formação, de modo a compreender se esta se constituiu como uma experiência empoderante ou se, pelo contrário, contribuiu para o aumento da sua vulnerabilidade enquanto pessoas desempregadas. Este artigo vem dar resposta à escassez de investigação centrada nas formações inseridas no âmbito das medidas ativas de emprego e à ausência de estudos que analisem o modo como as questões da cidadania e mercado de trabalho são conceptualizadas por pessoas envolvidas neste tipo de formação.

O artigo inicia-se com um breve enquadramento sobre a importância da formação em situações de desemprego, para, seguidamente, explorar teoricamente a relação entre formação e mercado de trabalho e, por fim, a tríade formação, mercado de trabalho e cidadania. Em seguida, apresentam-se os objetivos do estudo, descreve-se o método de recolha empírica, caracterizam-se os/as participantes e explica-se o procedimento de análise de conteúdo das entrevistas realizadas. Os principais resultados da análise dos discursos dos/as participantes serão apresentados e, finalmente, discutidos na última parte do artigo. 


\section{A Formação de Pessoas Adultas em Situação de Desemprego}

A partir dos anos 60/70 a UNESCO (Organização das Nações Unidas para a Educação e Ciência) promoveu práticas de formação para a população adulta, conferindo credibilidade social e académica à educação de adultos (FINGER, 2005) e dando ênfase ao processo de formação para responder aos novos desafios laborais. Entende-se, neste período, que a formação é procurada devido aos desafios laborais com que os/as adultos se deparam e não tanto por possíveis lacunas no seu percurso académico (SANZ FERNÁNDEZ, 2005). No caso português, a educação de adultos foi originalmente estimulada por iniciativas populares no período pós-25 de abril, independentes dos poderes públicos estatais. A progressiva tutela governamental das políticas de educação de adultos tem-se traduzido numa "história de alternância de políticas sem alternativa social” (TÁVORA, VAZ e COIMBRA, 2012, p. 34), afastada da natureza humanista que esteve na sua origem e crescentemente informada por lógicas compensatórias e orientações políticas frágeis. Este cenário enquadra-se num quadro mais amplo de transformações complexas nos modos de organização do trabalho, definido por novas e crescentes instabilidades sociais e individuais (COIMBRA e GONÇALVES, 2002).

As questões do emprego e da formação têm vindo a ser alvo de crescente preocupação por parte dos responsáveis pelas políticas públicas. Segundo a PORDATA (2019), 17,2\% dos/as portugueses encontrava-se, em 2018, em situação de pobreza (após transferências sociais). Ainda que as experiências de desemprego e de pobreza não se sobreponham necessariamente, o desemprego é um dos fatores mais determinantes no que concerne ao problema da pobreza (CALEIRAS, 2011). É em torno do trabalho que o sujeito se relaciona com o mundo e organiza as suas relações sociais (ARAÚJO e JORDÃO, 2011). De facto, a atividade profissional tem vindo, crescentemente, a assumir-se como elemento estruturador da vida humana e garante identitário (COIMBRA e GONÇALVES, 2002). A investigação evidencia que as pessoas em situação de desemprego sentem, frequentemente, uma sensação de fracasso, principalmente quando a duração do desemprego se prolonga (LOISON, 2003). Pessoas com emprego poderão também experienciar insatisfação; no entanto, ter um salário significa a existência de recursos económicos que permitem ter margem de escolha e, portanto, alguma liberdade (ARAÚJO e JORDÃO, 2011). A revisão da literatura focada na formação subsidiada mostra, por um lado, que este tipo de formação pode ter um papel importante no acesso ao mercado de trabalho de jovens adultos (RAMOS, 2007) mas, por outro lado, pode revelar-se ineficaz na obtenção de emprego na área da formação realizada (SILVA, 2015).

No que se refere às diferenças de género, os estudos indicam que as mulheres associam o trabalho a uma maior liberdade (ao trabalhar fora de casa deixam os limites do trabalho doméstico), enquanto os homens, pelo contrário, veem o trabalho como forma de ganhar dinheiro e de sustentar o agregado familiar (LOISON, 2003). Relativamente a diferenças de idade, a situação de desemprego tende a ser mais pensosa para sujeitos que estão a meio da sua vida profissional, ou seja, entre os 40 e os 50 anos de idade (BURNAY, 2000). O tipo de 
trabalho que o indivíduo tinha antes do desemprego também tem implicações, ou seja, "quanto maior for a diferença entre a situação profissional passada e/ou esperada e as formas de ocupação durante o desemprego (...) mais dificilmente é vivido o desemprego” (LOISON, 2003, p.122).

Considerando-se o emprego como forma crucial de inserção social, a educação e a formação profissional constituem, à partida, um mecanismo potenciador da empregabilidade e, por essa via, da coesão social. Em Portugal, apesar dos importantes investimentos em educação realizados nos últimos anos, visíveis nas despesas públicas consagradas à educação e formação, os níveis de abandono escolar precoce e os baixos níveis de qualificação da generalidade da população portuguesa ativa continuam problemáticos (RAMOS, 2007).

\section{Relação entre Formação e Mercado de Trabalho}

O atual contexto socioeconómico, caracterizado essencialmente pelo aumento da concorrência, da competitividade e da volatilidade dos mercados, tem coagido as organizações a introduzir mudanças (ALVES, 2008). Paralelamente, a incerteza de conseguir um trabalho e o confronto com a necessidade de adaptação a uma nova realidade são desafios cada vez mais exigentes na promoção da empregabilidade (RIBEIRO, 2018). Nesse sentido, os cursos de formação tendem a ser reconfigurados em função das transformações que decorrem ao nível do mercado de trabalho. Com efeito, Lima (2007) sublinha que o apelo constante à formação e à aprendizagem ao longo da vida tende a ser orientado para a adaptabilidade e a empregabilidade, colocando o ónus no indivíduo, a quem cabe a responsabilidade pela aquisição de saberes e competências. Neste sentido, critica-se uma conceção de aprendizagem vinculada ao padrão de acumulação de capital, que arrisca o esvaziamento da função problematizadora da educação e, consequentemente, o estreitamento do espaço para formação de uma consciência política sobre a realidade do desempregado (MACHADO e PALUDO, 2014).

Sabe-se que em 2018, de acordo com os dados do Observatório das Desigualdades, $11,8 \%$ da população portuguesa entre 18 e 24 anos, com nível de escolaridade completo ao $3^{0}$ ciclo do ensino básico, abandonou precocemente percursos de educação e formação, registando neste campo uma das mais altas taxas a nível europeu. Os cursos de formação para jovens e adultos são, portanto, frequentemente considerados centrais no incremento da empregabilidade.

Num estudo realizado por Ávila (2008), conclui-se que os sujeitos que integraram um processo RVCC desenvolveram novas competências, considerando que esse processo lhes tinha proporcionado melhores condições de empregabilidade a longo prazo. Noutro estudo realizado com 105 formandos/as (desempregados/as), focado nas questões da motivação, verificou-se que os/as formandos que terminavam o processo formativo estavam globalmente mais motivados/as do que os/as que o iniciavam, corroborando a ideia de que os/as adultos se sentem mais motivados/as se compreenderem claramente as vantagens e benefícios associados à aprendizagem adquirida (CARDOSO, 2012). Por outro lado, a investigação de 
Caleiras (2011) salienta que os programas de formação são muitas vezes usados para prolongar as prestações de desemprego ou obter graus escolares superiores, podendo, portanto, desviar-se do objetivo inicial que seria preparar para o mercado de trabalho e emprego. Neves (2012) aponta ainda que o principal motivo que leva um/a adulto a voltar a estudar é o facto de ter sido reencaminhado pelo IEFP por estar desempregado: "Este item constituiu-se como um fator indicador de que os adultos que recebem do Estado um rendimento são, por isso, indiciados pelo mesmo a frequentar uma formação” (p. 45).

\section{Relação entre Formação, Mercado de Trabalho e Cidadania}

A formação pode ser fundamental na aquisição de conhecimento, com repercussões em termos de mercado de trabalho, mas também ao nível da cidadania. Tal como refere Melo (2001, p. 139), “a pessoa só se torna pessoa graças às suas permanentes inter-relações com os mundos em que se integra — o mundo das gentes e o mundo das coisas — isto é, através, respetivamente, da [p]olítica e do trabalho”. Um estudo realizado por Malafaia e colegas (2012) mostrou que o cumprimento de deveres e obrigações, o obedecer às leis, o ser ativo na comunidade e o pagamento de impostos foram os fatores mais salientados por jovens, de origem nacional e imigrante, no que se refere a "ser um bom cidadão". Os resultados mostraram que, apesar de experiências cívicas e políticas diversas, a visão da cidadania democrática como prática e exercício de politização tende a ser dominada por uma visão excludente da cidadania como estatuto, entre quem é ou não cidadão/ã de primeira classe, que conduz à agudização da discriminação de grupos com menos voz na esfera pública e política. Com efeito, a cidadania, enquanto noção altamente contestada, deve ser problematizada a partir do reconhecimento das suas dimensões tensionais: de inclusão e exclusão, de diversidade e homogeneidade, de pertença e diversidade (FERREIRA, COIMBRA e MENEZES, 2012). No campo da formação de adultos, Torres (2003) defende que a formação capacita os indivíduos para o exercício da cidadania de uma forma mais ampla e integrada na sociedade atual, uma vez que o domínio da escrita, da leitura e da matemática é uma forma de incluir cidadãos inabilitados para sobreviver numa sociedade dominada pelas novas tecnologias, informação e consumo. Numa análise a participantes de cursos de educação e formação de adultos (EFA), realizado por Amorim (2006), conclui-se que, após a experiência de formação, tanto o sentido crítico como o interesse político dos formandos aumentaram.

O papel humanista da educação e formação tem vindo a ser desafiado por reconfigurações políticas e por contextos de crise socioeconómica, tendo a mais recente, em 2008, afetado significativamente os países do sul da Europa, como Portugal. Mueller (2017) argumenta que "a educação de forma geral foi sendo historicamente transformada e minimizada a um conjunto de aptidões e competências necessárias exclusivamente à obtenção de um posto de trabalho e que, consequentemente, vem perdendo sua função primordial em termos de formação humana” (p. 1). Assim, num momento em que o trabalho ganha um peso crescente como organizador social e identitário - estando, portanto, 
intimamente ligado às dinâmicas de procura de formação - a configuração das relações de trabalho por situações de precariedade e desemprego tem implicado profundas consequências em termos de cidadania (BRANDÃO e MARQUES, 2013). Segundo Crouch e colegas (2001), partindo da análise dos efeitos subjacentes à redefinição das relações de poder entre Estados e mercados, decorrentes das dinâmicas de globalização e liberalização económica, assistimos a um "novo triunfo do mercado sobre a cidadania” (p. 11). Num quadro europeu em que as reformas do estado social limitam os direitos sociais (LISTER, 2002), e em que o mercado de trabalho adquire centralidade como plataforma de integração social (BRADLEY e VAN HOOF, 2005), de que forma é que a cidadania é concetualizada pelos indivíduos? De que modo é que a transitoriedade profissional e a impossibilidade projetual influenciam a construção de si enquanto cidadãos/ãs? Em última análise, importa explorar o impacto de narrativas políticas que, em Portugal como nos restantes países europeus, parecem mais focadas na 'ativação de cidadãos/as', responsáveis por se tornarem empregáveis, e menos focadas na garantia social do direito ao trabalho (DAHLSTEDT, 2013).

\section{Objetivos do estudo}

O objetivo geral consistiu em analisar a relação entre as conceções de cidadania e de mercado de trabalho de pessoas que frequentam formações subsidiadas no âmbito da medida "Vida Ativa"1 do Instituto de Emprego e Formação Profissional, em Portugal. O objetivo geral integra quatro objetivos específicos: i) Compreender o percurso formativo e profissional de pessoas que frequentam formações subsidiadas; ii) Identificar os modos como as formações subsidiadas são perspetivadas pelas pessoas que as frequentam; iii) Aceder às conceções de cidadania de pessoas que frequentam formações subsidiadas e iv) Explorar as conceções de mercado de trabalho de pessoas que frequentam formações subsidiadas.

\section{Método}

Tendo em conta os objetivos definidos, optou-se por uma metodologia qualitativa para se analisar os discursos dos/as participantes acerca da formação, cidadania e mercado de trabalho. Segundo Bogdan e Biklen (1994), a metodologia qualitativa "exige que o mundo seja examinado com a ideia de que nada é trivial, que tudo tem potencial para construir uma pista que nos permita estabelecer uma compreensão mais esclarecedora do nosso objeto de estudo” (p. 49). Assim, uma abordagem qualitativa permitir-nos-á, a partir dos discursos dos sujeitos, explorar a existência (ou não) das relações conceptuais identificadas a partir da literatura, mas também perscrutar novas relações e questões a partir do significado que os/as participantes atribuem às suas experiências (KVALE e BRINKMAN, 2009).

Para a recolha de dados foram conduzidas entrevistas semiestruturadas com base num guião elaborado e preparado previamente, que serviu de ponto de partida e de orientação com 
o objetivo de criar espaço e condições para que os/as participantes pudessem desenvolver as suas ideias sobre formação, cidadania e mercado de trabalho. O guião foi dividido em cinco blocos temáticos para uma melhor orientação: i) apresentação do/a formando/a, ii) experiência na formação, iii) conceções de cidadania, iv) representações sobre o mercado de trabalho, e v) expetativas e recomendações acerca da formação.

As entrevistas, realizadas nos primeiro meses de 2019, foram previamente agendadas com os/as participantes através de contactos informais, seguindo um procedimento em bola de neve, em que se pedia a cada participante que nomeasse outra(s) pessoa(s) com características similares, que combinassem com os critérios amostrais. Uma vez que as entrevistas não foram realizadas em nenhum tipo de contexto institucional (por exemplo, no IEFP), estes contactos informais e o tipo de amostragem nomeada (em bola de neve) tornaram o processo desafiante, com alguns avanços e recuos. Todas as entrevistas foram gravadas e, posteriormente, transcritas. Todos/as os/as participantes foram esclarecidos/as sobre a natureza e a finalidade da investigação, tendo assinado um termo de consentimento informado.

Para a análise e interpretação dos dados obtidos foi realizada uma análise de conteúdo com recurso ao programa NVivo, o que facilitou a codificação e análise dos dados, tornandoa mais fluida e dinâmica, possibilitando a constante reconfiguração da árvore categorial que foi sendo construída. Esta árvore foi inspirada nos quadros de referência teóricos explorados ao longo do trabalho (AMADO, COSTA e CRUSOÉ, 2017), assim como por zonas não antecipadas mas apontadas pelo material empírico.

\section{Participantes}

As entrevistas foram conduzidas com dez sujeitos, com idades compreendidas entre os 25 e os 56 anos. Apesar do esforço em tornar a amostra o mais equilibrada possível em termos de género, oito são mulheres e dois são homens. No que se refere às habilitações literárias dos/as participantes, sete pessoas completaram o $9^{\circ}$ ano de escolaridade, duas pessoas completaram o $12^{\circ}$ ano, e uma pessoa tem curso superior.

Os/as participantes foram recrutados/as tendo em conta dois critérios principais: estar em situação de desemprego e a frequentar uma formação subsidiada do IEFP.

\section{Tratamento e análise de dados}

Para dar início à análise de dados, as entrevistas transcritas foram codificadas e categorizadas. Num primeiro momento, procedeu-se a uma leitura flutuante das transcrições e, posteriormente, a uma leitura mais atenta e pormenorizada, com vista a esboçar as principais categorias. A partir daqui, foram surgindo subcategorias e o desdobramento do texto em unidades de sentido. As categorias analíticas - algumas pré-definidas a partir de temas do guião, outras emergentes no decorrer da análise - seguem as regras da exaustividade, exclusividade, homogeneidade, pertinência, objetividade e produtividade (AMADO, COSTA e CRUSOÉ, 2017). 
Assim, depois de várias reformulações, foram definidas cinco categorias principais, das quais emergiram várias subcategorias. A seguinte árvore categorial ilustra o conjunto de categorias e respetivas subcategorias decorrentes da análise de conteúdo:

1. "Percurso educativo e profissional", com as subcategorias "percurso de educação e formação", "percurso profissional” e "experiência de desemprego";

2. "Perspetivas e experiências de formação", com as subcategorias "motivações e expectativas”, “obrigatoriedade das formações” e "clima de formação", "aprendizagens”, "organização e gestão da formação" e "sugestões de mudança”;

3. "Experiências e conceções de cidadania ativa", com as subcategorias "estar em formação", "ter emprego", "fazer voluntariado e doações”, "pagar impostos", "participar em manifestações”, "votar” e "pertencer a partidos políticos”;

4. "Experiências e conceções de mercado de trabalho", com as subcategorias "perceções sobre o mercado de trabalho atual”, "relação entre mercado de trabalho e formação", experiências profissionais positivas" e "experiências profissionais negativas";

5. "Expectativas sobre o futuro", com as subcategorias "nível formativo e educacional" e "nível profissional”.

Na secção seguinte apresentam-se exemplos de excertos ilustrativos dos principais resultados de cada uma das categorias. Todos os nomes utilizados são fictícios, de modo a proteger o anonimato dos/as participantes e garantir a confidencialidade dos dados.

\section{Principais resultados}

\section{Percurso educativo e profissional}

A análise das entrevistas permitiu verificar que o abandono escolar é várias vezes referido como fazendo parte do percurso da maioria dos sujeitos entrevistados, não só por opção, mas também devido à falta de recursos financeiros:

Completei só o $9^{\circ}$ ano, infelizmente (...). Na altura não me apetecia muito... (risos) Não, a verdade é que as coisas em casa não estavam muito fáceis, eu moro com os meus pais ainda e tenho, claro, que ajudar com as despesas, e como não estava muito fácil na altura eu decidi ir para um call center, em part-time, para começar a ter algum dinheiro. (Fábio)

Permitiu também verificarmos, entre os participantes no estudo, casos de frequência da escolaridade apenas até ao $9^{\circ}$ ano, assim como experiências formativas ligadas a iniciativas governamentais que visam promover a qualificação da população adulta. Constata-se a prevalência de percursos de educação e formação intermitentes e ziguezagueantes relacionados com contextos familiares e socioeconómicos adversos e ligados a experiências em diferentes sistemas de educação e formação: 
Estudei até ao $9^{\circ}$ ano no ensino normal... onde reprovei nas provas... nos exames finais (...) acabei o $9^{\circ}$ ano através também do... das Novas Oportunidades. (Lídia) $\mathrm{Na}$ altura as coisas não eram como eram agora... as coisas eram mais difíceis, era a filha mais velha, a minha mãe ficou cancerosa e....alguém tinha de trabalhar. O meu pai também ficou doente nessa altura, ficaram os dois, e eu achei por bem ajudar. (Sandra)

Verificou-se ainda na análise empírica, a existência de experiências profissionais passadas diversificadas quanto à duração e ao local de trabalho, sendo que os/as participantes se encontravam em situação de desemprego por razões sobretudo associadas às repercussões da crise económica e financeira que, em vários casos, culminaram em processos de insolvência, associando a essa experiência sentimentos negativos como angústia, depressão, insegurança e baixa autoestima:

Estive durante 9 anos numa empresa que fechou, entrou em insolvência... por isso é que eu vim aqui parar ao IEFP. Se não fosse assim, nunca estava aqui. (Lurdes) “Estive desempregada dois anos. É, vai fazer agora para julho, três anos que eu estou desempregada (...) eu acho que nem toda a gente pensa como eu mas eu sentia-me uma parasita... parecia que estava a roubar, eu em casa, sem trabalhar e a receber o subsídio de desemprego... eu não me sentia muito bem. (Isabel)

\section{Perspetivas e experiências de formação}

Nesta categoria, observa-se que alguns/as dos/as participantes consideram a formação como uma experiência que lhes possibilitará aumentar o seu nível académico e, consequentemente, melhorar o percurso profissional:

Queria ter os conhecimentos porque (...) nem digo só para a área que estou a tirar a formação, mas mesmo para outras áreas, toda a gente está a pedir o $12^{\circ}$ (...). Foi-nos dito no Centro de Emprego que cada vez mais eles dão oportunidade a quem tenha experiência e o $12^{\circ}$. Ou seja, uma coisa completa a outra. (Andreia)

Não obstante, a maioria dos/as participantes revelou também que a experiência ficou aquém das expectativas, não identificando relevância prática nas formações:

Fiz uma formação em técnico de administração. Pronto...era assim a única ligada, mais ou menos, à área da gestão...achei que poderia ser interessante $e$ pronto, acabei por fazê-la, mas confesso...no final não...não achei que fosse tão relevante como eu achei que na verdade estava originalmente a pensar. (Tiago)

Verifica-se igualmente que a obtenção do subsídio de desemprego, que supõe a frequência obrigatória da formação, é muito relevante e constitui-se como principal motivação para os/as participantes: 
as pessoas então têm de estar lá, senão como é que põem comer na mesa? Porque mesmo que não tenham subsídio de desemprego, acabam por lá estar a receber, sejam as bolsas ou algum tipo de rendimento que conseguem absorver dali (...) subsídios de transporte e de alimentação. (Francisca)

No entanto, não concordam com a obrigatoriedade das formações, por não se articular com o percurso, interesses e motivação de cada pessoa e, principalmente, por não respeitar a liberdade de escolha individual:

Isso foi-nos dito logo na primeira sessão, em que eu fiz questão de mostrar o meu descontentamento e dizer "isto não é para mim" $e$ "não quero este curso" ...e alguém se virou para mim e disse "pronto, não quer, não quer, é-lhe cortado o subsídio". Acho que é injusto... acho que é injusto porque eu se tenho subsídio é porque eu descontei, é porque eu trabalhei, acho muito injusto (...). Acho que as pessoas não deviam ser obrigadas... acho que as coisas funcionavam melhor se as pessoas viessem de livre vontade. (Sandra)

Durante as entrevistas surgiram também vários discursos a criticar o facto de existirem turmas com formandos de diferentes idades e experiências e motivações muito distintas, tornando a convivência mais desafiante:

Acho que não devia ser tudo ao molho e fé em Deus como é aqui (...). Devia haver uma triagem melhor. Depois as turmas são muito... pessoas muito diferentes, já somos adultos, já temos a nossa personalidade e não é fácil... de início foi terrível, apeteceu-me desistir montes de vezes (...) depois chegamos à formação, mesmo que o formador seja muito bom e queira realmente ensinar, às vezes tem de abrandar o ritmo, porque depois vê que $A, B$ e C não conseguem acompanhar (...) e começo a ficar frustrada porquê? Porque estou sempre a mastigar a mesma treta e não saímos disto... é um bocado desmotivante. (Sandra)

Relativamente às aprendizagens adquiridas no âmbito da formação, a maioria dos/as participantes realça ter melhorado a forma como se relaciona com os outros, mas sublinha também o aumento de conhecimentos e de competências técnicas:

Existem também módulos sobre comunicação e relações interpessoais que não servem só a nível profissional, mas no dia a dia com a nossa família, com os nossos amigos, com todos os tipos de relações que temos que... que... podemos não dar muito valor, mas há ali informação muito valiosa. (Eduardo) Elaborar uma carta, ou fazer um trabalho PowerPoint. Agora já me desenrasco mais ou menos. Para mim já foi uma vantagem (risos). Só por isso já valeu a pena (risos). (Isabel) 
Apesar de os/as participantes verem, no geral, vantagens em frequentar a formação, verificam-se também algumas críticas no que se refere à forma como os módulos estão organizados, à carga horária exigida e à incipiente componente prática envolvida:

Há alguns módulos que têm temas e conteúdos que inevitavelmente acabam por se repetir (...). Um desses módulos poderia ter uma carga horária inferior e outros módulos muito importantes podiam ser aumentados. (Eduardo)

Pensei que tinha coisas práticas para a gente aprender (...) acho que é uma coisa que devia ter o curso todo, ter mais prática (...) acho que acaba por ser massacrante para as pessoas que estão aqui... contrariadas. (Lídia).

\section{Experiências e conceções de cidadania ativa}

Sobre esta categoria importa assinalar que, durante a entrevista, foram mostradas seis imagens representando fenómenos que a literatura indica estarem associados às conceções de cidadania (LISTER, SMITH, MIDDLETON e COX, 2003; MENEZES, RIBEIRO, MALAFAIA, FERNANDES-JESUS \& FERREIRA, 2012). Aqui inclui-se a participação cívica e política, desde formas mais e menos convencionais, até ao envolvimento comunitário e partidário. A assunção de que a cidadania plena está intimamente dependente do cumprimento de deveres e obrigações (como, por exemplo, ter emprego e pagar impostos) tem sido reportada pela investigação realizada com grupos excluídos ou marginalizados (LISTER, SMITH, MIDDLETON e COX, 2003; MALAFAIA, FERNANDES-JESUS, RIBEIRO, NEVES, FONSECA \& MENEZES 2012). Assim, foi pedido aos/às entrevistados/as para escolherem três dessas imagens que representassem o que é para si ser um/a bom/a cidadão/ã, justificando as suas escolhas. As imagens representavam as seguintes opções: 'estar em formação', 'ter um emprego', 'fazer voluntariado e doações', 'pagar impostos', 'participar em manifestações' e 'votar'.

A escolha das imagens foi diversa entre os/as participantes, tal como a justificação dada, ainda que se tenha destacado uma noção de cidadania fortemente vinculada a deveres e obrigações e assente mais na dimensão do estatuto do que na dimensão da prática, o que se refletiu no facto de imagens como o ato de 'votar, 'ter emprego', 'pagar impostos' e 'estar em formação’ terem sido as mais escolhidas:

Acho que o votar dá-nos esse poder para depois sermos críticos do que a nossa sociedade tem de bom e de mau, porque estivemos lá presentes e votamos no que achamos que era melhor..., portanto, acho que isso faz parte de ser um bom cidadão...poder ter o direito de escolher em quem é que se vota. (Tiago)

Trabalhar porque tens de pagar impostos...tens de contribuir, não é? Temos de contribuir para o bolo... (risos) não é? e se não houvesse trabalhadores, quem é que fazia o trabalho? Quem é que varria o lixo, quem é que trabalhava a fazer peças numa fábrica? (Lurdes) 
todos nós devíamos pagar [impostos] e não fugir como tentamos fugir. Porque eu também fujo. Não é? Eu também fujo. Mas acho que... se toda a gente cumprisse, as coisas seriam ainda melhores. (Sandra)

Estudar nunca é tarde, as coisas vão alterando, a gente tem de ir acompanhando, senão quando damos por ela estamos desarmados para a vida. (Andreia)

Em síntese, oito dos/das dez participantes optaram pela imagem correspondente ao ato de 'votar', seis optaram pela imagem que ilustra 'ter emprego', cinco optaram por 'pagar impostos' e cinco por 'estar em formação'. Apenas três participantes optaram pela imagem de 'participar em manifestações’ e 'fazer voluntariado e doações'.

\section{Experiências e conceções de mercado de trabalho}

Um dos resultados que mais se destaca nesta categoria é a perceção de oportunidades de emprego em algumas áreas que os/as participantes dizem existir atualmente, apesar do acesso difícil (devido à crescente exigência de experiência profissional e qualificações académicas) e da precariedade das condições laborais. Além do mais, também se sugere a descoincidência entre a formação que estão a realizar e essas mesmas oportunidades:

Há bastantes oportunidades... não digo nesta área, nesta área não estou muito por dentro ainda do assunto, mas noutras áreas sim. O meu marido ainda agora está a sair de uma empresa e não lhe faltam oportunidades para trabalhar porque são trabalhos de marceneiro, está a entender? (Andreia)

Hoje em dia está mau. O trabalho é precário, x meses numa empresa e mandam as pessoas embora... não há aquela efetividade, não é? É trabalho a prazo... não é fácil (...) este mundo de trabalho agora assusta-me um bocadinho (...) São politiquices... lá está, por exemplo, as pessoas que estão na universidade, como é que querem que as pessoas adquiram experiência se não as deixam trabalhar? Uma pessoa para trabalhar tem que ter experiência, não é de um dia para o outro... não é? (Lurdes)

Relativamente à dificuldade de inserção no mercado de trabalho, os/as participantes assinalam ainda que os jovens/recém-licenciados e as pessoas mais velhas são os grupos mais afetados:

acho que o mercado de trabalho está muito difícil para jovens... jovens licenciados (...) é muito, muito difícil arranjarmos o primeiro emprego porque esperam logo que, ao sairmos da Universidade, tenhamos logo essa experiência na área, então não é muito fácil. (Tiago)

está um bocadinho difícil... eles exigem experiência... hum... se a pessoa não tiver experiência, não chamam (...) e depois também temos ofator idade. Que complica muito. Chega-se a partir de uma certa idade... somos muito novas para ter reforma e somos muito velhas para trabalhar. (Ana) 
A desvalorização e discriminação profissional também foram aspetos salientados, nomeadamente no que se refere à diferença remuneratória e valorização social entre quem tem ou não formação superior, denunciando-se uma clara distinção social:

Acho que desvalorizam um bocadinho as pessoas. E, ao desvalorizar... também massacram, por exemplo, as confeções (...) acho que na nossa sociedade, nesse tipo de trabalhos, somos vistos como... coitadinhos, pobres, não estamos integrados naquela classe... dita, alta. E acho que isso desvaloriza um bocadinho o trabalho que é feito, nos pagamentos já se nota isso (...). Só veem muito a classe dos doutores, que não passam de pessoas como nós, só por dizer que têm um canudo. (Lídia)

Quanto ao papel da formação no processo de inserção no mercado de trabalho, a maioria dos/as participantes considera que esta pode ter uma influência positiva na medida em que fornece competências e ferramentas essenciais para exercer determinadas funções, bem como para um bom desempenho nas entrevistas de emprego:

as formações dão-nos conhecimentos teórico-práticos para depois sermos capazes de exercer uma determinada profissão ou determinada função... Para já é imprescindível ter o $12^{\circ}$ ano para conseguir arranjar um bom emprego... $e$ depois sim, principalmente no meu caso, com esta formação que estou a tirar, penso que me vai abrir portas para a área da Restauração. (Fábio).

Nós temos módulos que nos ensinam como nos comportarmos dentro de uma entrevista de emprego... o estar, o saber estar, o saber falar, pronto e esses módulos, essas disciplinas ensinam-nos a maneira como nos havemos de comportar numa entrevista. (Isabel)

Por último, destaca-se ainda, nos discursos dos/as participantes, uma certa ambivalência quanto às experiências profissionais por que já passaram. Por um lado, relatam algumas experiências positivas, em que se destacam tipos de trabalhos nos quais estiveram envolvidos durante mais tempo e onde tinham contacto direto com o público. Por outro lado, também relatam algumas experiências negativas como os períodos de insolvência das empresas onde trabalhavam e as situações em que se sentiram desrespeitados/as no local de trabalho:

Houve uma altura na fábrica em que eu fazia transportes com clientes e lidava com os clientes, essa parte foi positiva, aliás lá está, o contacto com as pessoas (...) de positivo, há muitas situações de colegas, criam-se amizades para a vida, ainda hoje tenho amigos, um dos meus melhores amigos conheci-o lá na fabrica. (Eduardo)

Pela negativa, houve uma confeção em que eu trabalhei que... muito má, muito má, muito má. Tratavam as pessoas como lixo, não respeitavam ninguém, eu cheguei a ir ao Centro de Emprego fazer queixa dessa empresa. (Sandra)

\section{Expetativas sobre o futuro}


No que diz respeito a esta última categoria, observa-se que os/as participantes têm, no geral, baixas expectativas em arranjar emprego - tendo em conta, sobretudo o contexto social e económico adverso em que se encontram:

eu não estou assim 100\% convicta que vá depois, no fim do estágio, ficar a trabalhar nessa área. Até porque há pessoas a sair da faculdade, universidades, doutoramentos e assim e quer dizer, e às vezes estão no desemprego e... nós através disto, com a idade que já temos, iremos ter essa oportunidade? É um grande ponto de interrogação. (Andreia)

estamos a viver uma altura complicada desde há uns anos para cá em que temos ciclos económicos um bocadinho difíceis...nunca sabemos muito bem o que vai acontecer... acaba por não nos deixar pensar muito a tão longo prazo. (Tiago)

Ainda assim, alguns/as mostram vontade de continuar a investir na formação, seja por motivos financeiros ou por crescimento e desenvolvimento pessoal:

formação vou tentar sempre fazer...às vezes falo ao meu marido...porque ele gostava de saber falar Inglês, só arranha um bocadinho e disse-lhe "lembras-te quando eu andava a fazer os cursos de inglês, o que é que tu me dizias? Outro de Inglês? Olha, tivesses ido comigo porque agora faz-te falta...” (risos). Portanto, eu sempre investi um bocadinho... pode ser uma formação de 25h, não importa, a gente aprende sempre alguma coisa. Mesmo que seja só para relembrar o que já se aprendeu. (Francisca)

Eu tenho um sonho... gostava de ainda ir para a universidade. (Lurdes)

\section{Discussão e conclusão}

Os/s participantes neste estudo revelaram ter um percurso académico e profissional diversificado, bem como expectativas futuras e entendimentos distintos sobre a cidadania e o mercado de trabalho. No entanto, existem também alguns pontos em comum. Relativamente ao percurso formativo, verifica-se o abandono escolar precoce, tanto por opção, como por falta de recursos financeiros. A maioria estudou até ao $9^{\circ}$ ano, não tendo atingido o nível de escolaridade obrigatório. Tal como indica o estudo de Neves (2012), verifica-se que o principal motivo para um/a adulto voltar a estudar é o facto de ter sido reencaminhado pelo IEFP. No presente estudo, os/as participantes ingressaram na formação do IEFP devido ao carácter obrigatório da mesma e para não perderem o subsídio de desemprego. Apesar disso, houve participantes que viram na formação uma boa oportunidade de crescimento pessoal, académico e profissional. Estes dados corroboram os resultados da investigação de Caleiras (2011), onde o autor indica que os programas de formação são muitas vezes usados para prolongar as prestações de desemprego ou obter graus escolares superiores. Desta forma, é possível afirmar que a formação não está a ser utilizada de forma 
a preparar para o mercado de trabalho. Aliás, os/as participantes referem várias limitações destas formações, nomeadamente quanto à real consideração das expectativas de formação de cada pessoa, bem como dos diversos percursos e experiências individuais. Além disso, a descrença na eficácia destas experiências formativas na obtenção de emprego foi evidente, mesmo por parte de quem as avalia positivamente quanto à aprendizagem de novas competências técnicas e, até, relacionais.

Sobre o percurso profissional, pode constatar-se que existem experiências profissionais longas (no mesmo local) e também experiências profissionais curtas (em diferentes áreas), que culminaram em situações de desemprego. Em linhas gerais, pode afirmar-se que tanto o abandono escolar precoce como o desemprego conduziram, de algum modo, à frequência de uma formação subsidiada, em que os/as formandos/as procuraram aumentar o seu nível académico e melhorar a situação profissional num contexto social e económico adverso e cada vez mais exigente, com variações constantes nas características do mercado de trabalho (TÁVORA, VAZ e COIMBRA, 2012).

Quanto às características das formações subsidiadas e ao modo como estas foram vistas pelos/as participantes, a crítica à organização dos módulos e à respetiva carga horária foi o aspeto que mais se destacou. Todos os/as participantes consideraram que deveriam existir mais módulos práticos e menos módulos teóricos. De qualquer forma, as formações foram tidas como relevantes pela maioria, embora podendo não ser conducentes à inserção no mercado de trabalho.

É crucial que o carácter de “obrigatoriedade” destas formações seja analisado politicamente, sob risco de não estarem de facto a contribuir para a inserção no mercado de trabalho e, pelo contrário, estarem a reforçar a fragilidade social destas pessoas. Nesse sentido, parece assistir-se a uma organização social que sinaliza e distingue entre 'cidadãos/ãs de primeira classe’ e ‘cidadãos/ãs de segunda classe’. Estudos realizados têm já apontado o efeito potencialmente perverso das políticas de apoio à contratação de pessoas subsidiadas, mostrando inclusivamente que as entidades empregadoras tendem a não aderir a este tipo de medidas de ativação (BOTELHO, 2010; RIBEIRO, 2018). Aliás, sublinha-se que este paradigma de ativação pode estar a conduzir a efeitos opostos à sua génese, com consequências significativas em termos sociais e de cidadania. Como refere Paiva (2003), “o esquema das medidas ativas é percebido por muitos especialistas como um retrocesso da montagem do sistema de proteção social da cidadania, tanto pelo seu carácter compulsório, como pelo moralismo que está explícito na base da sua argumentação ideológica (pp. 101102). Posto isto, os/as entrevistados/as reconhecem a necessidade de renovação e reestruturação das formações do IEFP no sentido de existir uma maior componente prática, assim somo uma maior consonância com aos percursos individuais diferenciados e as diferentes motivações e interesses da população alvo. De facto, sobre este tipo de formações "questiona-se a real autonomia do[a] beneficiário[a] na construção do seu projeto de inserção” (RIBEIRO, 2018, p. 95).

No que diz respeito às conceções de cidadania de pessoas que frequentam formações subsidiadas, observa-se que, de uma forma geral, há uma prevalência de visões mais normativas e convencionais do que deve ser uma boa cidadania, ligada sobretudo a deveres 
e obrigações (votar, pagar impostos, ter emprego e estar em formação). Verifica-se que a maioria da amostra considera que ser um/a bom/a cidadão/ã significa ‘ter um emprego’ e, portanto, poder contribuir para a sociedade, o que leva a crer que as pessoas que se encontram em situação de desemprego consideram-se melhores cidadãos/ãs quando estão a trabalhar. Como é dito por um dos entrevistados, "o trabalho é peça fundamental da cidadania" (Eduardo). Por outro lado, uma parte significativa da amostra considera que uma pessoa que se encontra a realizar uma formação é, por isso mesmo, um/a bom/a cidadão/ã. Do mesmo modo, considera que ser um/a bom/a cidadão/ã implica pagar impostos e que, tal como o ato de 'votar', se trata de um dever cívico, corroborando o estudo de Malafaia et al. (2012) sobre a importância atribuída ao cumprimento de deveres e obrigações na consideração de uma cidadania de plenos direitos. As pessoas em situação de desemprego consideram-se bons/as cidadãos/ãs quando votam e quando pagam os seus impostos. Se considerarmos que este paradigma de ativação assenta numa lógica de moeda de troca, em que o Estado exige a ativação do indivíduo (que deve estar ou a trabalhar ou em formação) em troca do acesso a benefícios sociais, os/as participantes deste estudo parecem revelar uma internalização desses pressupostos. Com efeito, "defender a educação enquanto direito humano promotor dos demais direitos”, implica não só reconhecer a interligação entre as diversas dimensões das desigualdades sociais - a exclusão, a pobreza, o desemprego, etc. - (BARROS, 2018, p. 532), mas também analisar o modo como determinadas experiências formativas impactam na forma como as pessoas concebem a sua agência cívica e política. No que toca às medidas de ativação, enquadradas na nova geração de políticas sociais europeias, elas parecem ser caracterizadas por "conteúdos disciplinadores, punitivos e baseados em contrapartidas em relação aos benefícios recebidos” (MOSER, 2011, p. 68).

No que concerne às dimensões positivas associadas a estas formações, foi referido que a formação faz com que as pessoas em situação de desemprego se sintam cidadãos/ãs ativos/as na sociedade: o facto de estarem em formação concede-lhes um sentimento de inclusão na sociedade e de cidadania ativa. As aprendizagens, algumas técnicas e competências relacionais, foram também assinaladas e não devem ser negligenciadas, ainda que se indiquem as baixas expectativas em termos de reinserção profissional, reforçando resultados de outros estudos (e.g., SILVA, 2015). Como foi assinalado por alguns/as participantes, no caso de não arranjarem emprego, a opção pode ser a de continuar em ciclos de formação de forma a garantir rendimento. Expõem-se, assim, as contradições de um sistema formativo que "visa a inserção de pessoas em um mercado de trabalho precário, de curto prazo e socialmente desprotegido” (MOSER, 2011, p. 74). De acordo com os resultados apresentados, verifica-se que, apesar de as pessoas em formação terem conhecimento da existência de oportunidades em algumas áreas, consideram que essas oportunidades não são muitas vezes coincidentes com a área de formação em que se encontram envolvidos/as e que o mercado de trabalho atual é precário e exigente (em termos de experiência profissional e qualificações académicas, por exemplo). Estes são fatores que, na opinião dos/as entrevistados/as, levam à desigualdade e à discriminação, despojando-os/as de perspetivas de futuro. Torna-se evidente, como sugerido por Mueller (2017), que “uma suposta 'educação para o trabalho’ não dá mais conta de mitigar as contradições presentes na relação entre 
capital e trabalho” (p. 684). A realidade política e social atual deve ser tida em conta nesta análise, para se compreender de que forma os sistemas sociais de educação e formação se ajustam a conjunturas económicas complexas, que tendem a agudizar a exclusão e a vulnerabilidade social, económica e simbólica.

Sugere-se, assim, a realização de mais estudos, incluindo estudos com desenhos longitudinais que permitam analisar o impacto ao longo do tempo da frequência de formações obrigatórias na reinserção profissional dos/as participantes e na sua auto perceção enquanto cidadãos/ãs. Concordamos que "uma educação voltada para a construção de uma cidadania democrática não pode [continuar a] se orientar apenas por valores advindos das forças do mercado” (FILHO, 1998, p. 119). Com efeito, os consequentes impactos na agência democrática individual e coletiva precisam de ser analisados, de modo a "refundar, pela educação, a própria educação enquanto item político, para conquistar e manter através da sua praxis uma outra compreensão do papel do sujeito-cidadão em democracia” (BARROS, 2018, p. 533).

\section{Notas}

1. Medida Vida Ativa - criada pela Portaria n. ${ }^{\circ}$ 203/2013 de 17 de junho - pretende reintegrar, o mais rápido possível, os desempregados no mercado de trabalho, desenvolvendo competências pessoais, relacionais e profissionais, a fim de melhorar a empregabilidade das pessoas em formação (IEFP, 2019).

\section{Referências}

ALVES, N. Políticas de educação e formação para jovens: tensões e contradições. Perspetiva, Florianópolis, v. 26, n. 1, p. 209-230, 2008.

AMADO, J.; COSTA, A. P.; CRUSOÉ, N. A técnica da análise de conteúdo. In: AMADO, João (Ed.). Manual de Investigação Qualitativa em Educação. Coimbra: Imprensa da Universidade de Coimbra, 2017. p. 303350.

AMORIM, J. P. O impacto da Educação e Formação de Adultos no desenvolvimento vocacional e da cidadania - A metamorfose das borboletas. Lisboa: DGERT/MTSS, 2006.

ARAÚJO, P.; JORDÃO, F. “Os inempregáveis”: Estudos de caso sobre os impactos psicossociais do nãoemprego em licenciados portugueses. Análise Psicológica, Lisboa, v. 2, n. 29, p. 289-314, 2011.

ÁVILA, P. A literacia dos adultos: Competências-Chave na sociedade do conhecimento. Lisboa: Celta Editora, 2008.

BARROS, R. Silêncios e desafios da agenda para o desenvolvimento pós-2015 - reflexões sobre o papel da Educação Social Crítica. Currículo sem Fronteiras, v. 18, n. 2, p. 530-549, maio/ago. 2018.

BRADLEY, H.; VAN HOOF, J. Young people in Europe: Labour markets and citizenship. Bristol: Bristol University Press, 2005.

BOGDAN, R.; BIKLEN, S.. Investigação qualitativa em educação: Uma introdução à teoria e aos métodos. Porto: Porto Editora, 1994. 
BOTELHO, A. As políticas sociais para a inserção de grupos em desvantagem face aos mercados de trabalho: a génese da resposta sistémica do estado português. 2010. Tese (Mestrado em Política Social) - Instituto Superior de Ciências Sociais e Políticas, Universidade de Lisboa, Lisboa, 2010.

BRANDÃO, A. M.; MARQUES, A. P. Jovens, trabalho e cidadania: que sentido(s). Braga: Centro de Investigação em Ciências Sociais, Universidade do Minho, 2013.

BURNAY, N. Chômeurs en Fin de Parcours Professionnel. Avoir 50 ans, Être au Chômage. Paris: Delachaux et Niestlé, 2000.

CALEIRAS, J. (2011). Para além dos números - as consequências pessoais do desemprego: Trajetórias de empobrecimento, experiências e políticas. 2011. Tese (Doutoramento em Sociologia) - Faculdade de Economia, Universidade de Coimbra, Coimbra, 2011.

CARDOSO, F. (2012). A contribuição do Programa Novas Oportunidades para o desenvolvimento da motivação e auto-estima dos formandos que o frequentam - Estudo de Caso. 2012. Tese (Mestrado em Psicologia) - Universidade Portucalense, Porto, 2012.

CARRÉ, P. De la motivation à la formation. Paris: L'Harmattan, 2001.

CASTRO, J. M.; IMAGINÁRIO, L. Psicologia da formação profissional e da educação de adultos. Porto: LivPsic, 2001.

COIMBRA, J.; GONÇALVES, C. Significados construídos em torno da experiência profissional/trabalho. In: Atas do IV Congresso Internacional de Formação Norte de Portugal/Galiza: Integração das políticas e sistema de educação e formação - Perspetivas e Desafios. Porto: Instituto do Emprego e Formação Profissional, 2002. p. 353-366.

CROUCH, C.; EDER, K.; TAMBINI, D. Citizenship, Markets, and the State. Oxford: Oxford University Press, 2001.

DAHLSTEDT, M. The Politics of Labour Market Activation: Employability, Exclusion and Active Citizenship. Revija za Sociologiju, Zagreb, v. 43, n. 1, p. 5-29, 2013.

FERREIRA, P. D.; COIMBRA, J. L.; MENEZES, I. "Diversity within diversity” - exploring connections between community, participation and citizenship. Journal of Social Science Education, Bielefeld, v. 11, n. 3, p. 118-132, 2012.

FILHO, J. C. P. Cidadania e Educação. Cadernos de Pesquisa, n. 104, p. 101-121, jul. 1998.

FINGER, M. A educação de adultos e o futuro da sociedade. In: CANÁRIO, Rui; CABRITO, Belmiro (Org.). Educação e Formação de Adultos: Mutações e convergências. Lisboa: Educa, 2005. p.15-30.

GONÇALVES, J. A. Desenvolvimento profissional e carreira docente - Fases da carreira, currículo e supervisão. Sísifo/Revista de Ciências da Educação, Lisboa, n. 8, p. 23-36, 2009.

KVALE, S; BRINKMAN, Svend.. InterViews: Learning the craft of qualitative research interviewing. Thousand Oaks: Sage, 2009.

LIMA, L. Educação ao longo da vida - Entre a mão direita e a mão esquerda de Miró. São Paulo: Editora Cortez, 2007.

LISTER, R. The dilemmas of pendulum politics: balancing paid work, care and citizenship. Economy \& Society, London, v. 31, n. 4, p. 520-532, 2002.

LISTER, R.; SMITH, N.; MIDDLETON, S.; COX, L. Young people talk about citizenship: empirical perspectives on theoretical and political debates. Citizenship Studies, London, v. 7, n. 2, p. 235-253, 2003.

LOISON, L. A Experiência do Desemprego em Portugal. Elaboração duma Tipologia. Cidades, Comunidades e Territórios, Lisboa, n. 6, p. 113-124, 2003.

MALAFAIA, C. Capital social e económico numa "escola de democracia": um estudo comparativo entre a Amnistia Internacional em Portugal e na Suécia (Tese de Mestrado, FPCEUP), 2011. Disponível em: https://catalogo.up.pt/F/?func=full-setset\&set_number=011952\&set_entry=000007\&format=999 
MALAFAIA, C.; FERNANDES-JESUS, M.; RIBEIRO, N.; NEVES, T.; FONSECA, L. \& MENEZES, I. Perspetivas e subjetividades sobre a participação política e cívica: jovens, família e escola. In: MENEZES, Isabel; RIBEIRO, Norberto; FERNANDES-JESUS, Maria; MALAFAIA, Carla; FERREIRA, Pedro (Eds.), Agência e participação cívica e política: jovens e imigrantes na construção da democracia. Porto: LivPsic, 2012. pp. 59-94.

MELO, A. Sessão de Encerramento. In: ANEFA, Educação e Formação de Adultos na Europa: as Competências-Chave para a Cidadania e a Empregabilidade. Textos e Comunicações. Lisboa: ANEFA, 2001. p. 137-140.

MENEZES, I.; RIBEIRO, N.; FERNANDES-JESUS, M.; MALAFAIA, C.; FERREIRA, P. Agência e participação cívica e política: jovens e imigrantes na construção da democracia. Porto: LivPsic, 2012.

MACHADO, R. C. F.; PALUDO, C. Educação de jovens e adultos (eja) e a relação trabalho/educação no trabalho de educação popular. Currículo sem Fronteiras, v. 14., n. 1, p. 137-150, jan/abr. 2014.

MOSER, L. A nova geração de políticas sociais no contexto europeu: workfare e medidas de ativação. Pesquisa Teórica, v. 14, n. 1, p. 68-77, jan/jun. 2011.

MUELLER, R. R. O novo (velho) paradigma educacional para o século XXI. Cadernos de Pesquisa, v. 47, n. 164, p. 670-686, abr./jun. 2017.

NEVES, M. Fatores do abandono escolar precoce e motivações para o regresso em educação de adultos. 2012. Tese (Mestrado em Psicologia da Educação) - Instituto Politécnico de Gestão e Tecnologia, Vila Nova de Gaia, 2012.

OBSERVATÓRIO DAS DESIGUALDADES (2018). Disponível em https://www.observatorio-dasdesigualdades.com/2018/06/12/abandono-precoce-de-educacao-e-formacao/

PAIVA, B. A tradução das medidas de política social como estratégias de combate à Exclusão Social: "Um campo de expectativas e esperanças”. In: RODRIGUES, Fernandes (Coord.). Acção social na área da exclusão social. Lisboa: Universidade Aberta, 2003. p. 91-106.

PORDATA (2019). Base de dados Portugal contemporâneo. Disponível em https://www.pordata.pt/

RAMOS, M C. Aprendizagem ao longo da vida. Instrumento de empregabilidade e integração social. Revista Portuguesa de Pedagogia, Coimbra, v. 41, n. 3, p. 299-333, 2007.

RIBEIRO, P. (2018). Uma cartografia de sentidos de inclusão social: Análise de políticas, dispositivos e discursos sobre exclusão social, educação/formação e emprego. 2018. Tese (Doutoramento em Ciências da Educação) - Faculdade de Psicologia e de Ciências da Educação, Universidade do Porto, Porto, 2018.

SANZ FERNÁNDEZ, F. Modelos actuais de educação de pessoas adultas. In: CANÁRIO, Rui; CABRITO, Belmiro (Orgs.). Educação e Formação de Adultos. Mutações e convergências. Lisboa: Educa, 2005. p.7396.

SILVA, M. Reinserção Profissional de Desempregados: O Papel da Formação Profissional na Reinserção de Desempregados no Mercado de Trabalho. 2015. Tese (Mestrado em Gestão Estratégica de recursos Humanos) - Escola Superior de Ciências Empresariais, Instituto Politécnico de Setúbal, Setúbal, 2015.

SILVESTRE, A. Educação/Formação de Adultos como dimensão dinamizadora do sistema educativo/formativo. Lisboa: Instituto Piaget, 2003.

SILVESTRE, A. Jovens, Trabalho e Políticas de Juventude. In: NEVES, T.; MALAFAIA, C. (Org.). Gestão de Conflitos: uma experiência, um guia. Porto: Livpsic, 2012. p. 17-30.

TÁVORA, A.; VAZ, H.; COIMBRA, J. A(s) crise(s) da formação e educação de adultos em Portugal. Saber \& Educar, Porto, n. 17, p. 28-40, 2012.

TORRES, C. A. Política para a educação de adultos e globalização. Currículo sem Fronteiras, v. 3, n. 2, p. 6069, 2003. 
VALADAS, C. Mudanças nas políticas: Do (des)emprego à empregabilidade. Revista Crítica de Ciências Sociais, Coimbra, n. 112, p. 89-110, 2014.

\section{Correspondência}

Luciana Lopes, Mestre em Educação e Formação de Adultos pela Faculdade de Psicologia e de Ciências da Educação da Universidade do Porto.

Orcid: https://orcid.org/0000-0001-5746-8702

E-mail: luciana_portugal@hotmail.com

Norberto Ribeiro, Doutor em Ciências da Educação pela Faculdade de Psicologia e de Ciências da Educação da Universidade do Porto (FPCEUP); Investigador e membro integrado do Centro de Investigação e Intervenção Educativas (CIIE), Universidade do Porto.

Orcid: http://orcid.org/0000-0001-7581-7902.

E-mail: norberto@fpce.up.pt

Carla Malafaia, Doutora em Ciências da Educação pela Faculdade de Psicologia e de Ciências da Educação da Universidade do Porto (FPCEUP); Investigadora e membro integrado do Centro de Investigação e Intervenção Educativas (CIIE), Universidade do Porto.

Orcid: http://orcid.org/0000-0001-5490-1187.

E-mail: carlamalafaia@fpce.up.pt

Autora para correspondência é Carla Malafaia, investigadora doutorada da Universidade do Porto, membro integrado do Centro de Investigação e Intervenção Educativas (CIIE). Faculdade de Psicologia e de Ciências da Educação da Universidade do Porto. Rua Alfredo Allen. Porto, 4200-135, Portugal.

E-mail: carlamalafaia@fpce.up.pt

\section{Reconhecimentos}

Norberto Ribeiro: É investigador júnior contratado no âmbito do CEEC Individual, com financiamento da Fundação para a Ciência e a Tecnologia (FCT), IP (CEECIND/02115/2018).

Texto publicado em Currículo sem Fronteiras com autorização dos autores. 